\title{
Hexamethonium attenuates sympathetic activity and blood pressure in spontaneously hypertensive rats
}

\author{
PENG LI* , JUE-XIAO GONG* ${ }^{*}$ WEI SUN, BIN ZHOU and XIANG-QING KONG \\ Department of Cardiology, The First Affiliated Hospital of Nanjing Medical University, \\ Nanjing, Jiangsu 210029, P.R. China
}

Received October 21, 2014; Accepted July 29, 2015

DOI: $10.3892 / \mathrm{mmr} .2015 .4315$

\begin{abstract}
Sympathetic activity is enhanced in heart failure and hypertensive rats. The aims of the current study were: i) To investigate the association between renal sympathetic nerve activity (RSNA) and mean arterial pressure (MAP) in response to intravenous injection of the ganglionic blocker hexamethonium; and ii) to determine whether normal Wistar rats and spontaneously hypertensive rats (SHRs) differ in their response to hexamethonium. RSNA and MAP were recorded in anaesthetized rats. Intravenous injection of four doses of hexamethonium significantly reduced the RSNA, MAP and heart rate (HR) in the Wistar rats and SHRs. There were no significant differences in the RSNA, MAP or HR between Wistar rats and SHRs at the two lowest doses of hexamethonium. However, the two highest doses of hexamethonium resulted in a greater reduction in the RSNA and MAP in SHRs compared with Wistar rats. There was a significant positive correlation between the alterations in RSNA and MAP in response to the intravenous injection of hexamethonium in the Wistar rats and SHRs. There were no significant differences in the timing of the maximal effects on RSNA, MAP or HR or in recovery following hexamethonium treatment. These results suggest that there is an association between the RSNA and MAP response to intravenous injection of hexamethonium and that the alterations in MAP in response to hexamethonium may be used to evaluate basal sympathetic nerve activity.
\end{abstract}

Correspondence to: Dr Xiang-Qing Kong or Professor Bin Zhou, Department of Cardiology, The First Affiliated Hospital of Nanjing Medical University, 300 Guangzhou Road, Nanjing, Jiangsu 210029, P.R. China

E-mail: xiangqing_kong@sina.com

E-mail: zhou_bin12@163.com

*Contributed equally

Key words: hexamethonium, sympathetic activity, mean arterial pressure, spontaneously hypertensive rats

\section{Introduction}

Numerous studies have demonstrated that sympathetic activity is enhanced in patients with essential (1) or secondary hypertension $(2,3)$ in addition to various hypertensive models including obesity (4), renovascular hypertensive rats (5) and spontaneously hypertensive rats (SHRs) (6). Several methods have been used to evaluate sympathetic activity including the cardiac sympathetic afferent reflex (7), the adipose afferent reflex (4), plasma norepinephrine levels (8) and blood pressure response to ganglionic blockade (9).

Hexamethonium is a ganglionic blocker that is used to treat hypertension $(10,11)$. It has been reported that hexamethonium produces a greater reduction in blood pressure in angiotensin II-induced hypertensive rats compared with saline-infused rats (12). Hexamethonium reduced bradycardia and the pressor response in Wistar rats and SHRs, and hexamethonium treatment in SHRs resulted in a greater reduction in blood pressure (13). However, the effects of hexamethonium on sympathetic nerve activity are not fully understood.

Touw et al (14) evaluated sympathetic activity in SHRs by measuring alterations in mean arterial pressure (MAP) in response to hexamethonium intravenous injection to block sympathetic nervous system (SNS) transmission, in order to evaluate the sympathetic activity in the SHRs. Sato et al (15) used absolute blood pressure as an index to evaluate peripheral SNS activity in deoxycorticosterone acetate-treated rats injected with hexamethonium. However, the precise association between sympathetic nerve activity and the blood pressure response to hexamethonium remains unclear. The current study aimed to examine renal sympathetic nerve activity (RSNA), MAP and the association between RSNA and MAP in response to intravenous injection of hexamethonium in normal Wistar rats and SHRs.

\section{Materials and methods}

Animals. Experiments were conducted on male normotensive Wistar rats and SHRs weighing 280-320 g obtained from Vital River Laboratory Animal Technology Co., Ltd. (Beijing, China). The procedures were approved by the Experimental Animal Care and Use Committee of Nanjing Medical University and complied with the Guide for the Care 
and Use of Laboratory Animals (16). All efforts were made to minimize the number of animals used and their suffering. The rats were anesthetized using an intraperitoneal injection of sodium pentobarbital $\left(50 \mathrm{mg} / \mathrm{kg}^{-1}\right)$ and ventilated with room air using a Harvard 683 Small Animal Ventilator (Harvard Apparatus, Holliston, MA, USA).

Systolic blood pressure (SBP) measurements. The tail artery SBP was measured in conscious rats using a Non-Invasive Blood Pressure monitor (ADInstruments, Bella Vista, Australia). To minimize stress-induced SBP fluctuations, the rats were trained by measuring SBP daily for a minimum of 10 days prior to surgery. The rats were warmed for 10-20 min at $28^{\circ} \mathrm{C}$ prior to the measurements to allow for detection of tail arterial pulsations and to achieve a steady pulse. The SBP was obtained by calculating the mean of 10 measurements.

$R S N A$ recording. A retroperitoneal incision was made and the left renal sympathetic nerve was isolated. The nerve was cut distally to eliminate its afferent activity and was placed on a pair of silver electrodes that were immersed in warm mineral oil. RSNA was amplified using an AC/DC Differential Amplifier Model 3000 (A-M Systems, Inc., Sequim, WA, USA) with a low frequency cut-off at $60 \mathrm{~Hz}$ and a high frequency cut-off at $3,000 \mathrm{~Hz}$ and integrated at a time constant of $0.1 \mathrm{sec}$. The raw RSNA, integrated RSNA, MAP and HR were simultaneously recorded on a PowerLab 8SP Data Acquisition System (ADInstruments). The background noise level was determined following sectioning of the central end of the nerve and was subtracted from the RSNA value, as previously described (5).

Chemicals. Hexamethonium hydrochloride was purchased from Sigma-Aldrich (St. Louis, MO, USA) and dissolved in normal saline (Shanghai Baxter Healthcare Co., Ltd., Shanghai, China). The concentrations selected for the current study were $0.2,1.0,5.0$ or $25.0 \mathrm{mg} / \mathrm{kg}$ body weight.

Intravenous injection. The femoral artery and vein were cannulated under sodium pentobarbital anesthesia to prepare for MAP recordings and the intravenous injection of hexamethonium. Saline or hexamethonium hydrochloride $(0.2,1.0$, 5.0 or $25 \mathrm{mg} / \mathrm{kg}$ body weight) was then injected into the vein using a PM2000B Cell Microinjector (MicroData Instrument, Inc., South Plainfield, NJ, USA). The effects of hexamethonium on RSNA, MAP and HR were determined by averaging 1 min of the maximal responses. The time course of the maximal effects on RSNA, MAP and HR were determined from the end of the injections to the maximum effect points. The recovery time from the hexamethonium effects on RSNA, MAP and HR were determined from the maximum effect points to the maximum recovery points. The recovery of hexamethonium effects on RSNA, MAP and HR was determined at the maximum recovery points by averaging the parameters for $1 \mathrm{~min}$.

Statistical analysis. Data were analyzed using SPSS software, version 18.0 (SPSS, Inc., Chicago, IL, USA). Comparisons between two observations were assessed by Student's paired t-test. One-way analysis of variance was used followed by the Bonferroni post hoc test for multiple comparisons. All data
Table I. Body weight, SBP, baseline MAP and baseline HR in Wistar rats and SHRs.

\begin{tabular}{lcc}
\hline Variable & Wistar & SHR \\
\hline Number & 30 & 30 \\
Body weight (g) & $303.7 \pm 4.8$ & $300.2 \pm 5.4$ \\
SBP (mmHg) & $118.8 \pm 3.5$ & $194.0 \pm 3.4^{\mathrm{a}}$ \\
Baseline MAP (mmHg) & $91.1 \pm 1.5$ & $132.2 \pm 2.2^{\mathrm{a}}$ \\
Baseline HR (beats/min) & $350.7 \pm 7.4$ & $357.2 \pm 7.7$ \\
\hline
\end{tabular}

SBP of the tail artery was measured in conscious rats using a noninvasive computerized tail-cuff system. The baseline MAP and HR were measured under anesthesia with a pressure transducer through a catheter placed in the femoral artery. Values are presented as the mean \pm standard error. ${ }^{a} \mathrm{P}<0.05$ vs. Wistar rats. SBP, systolic blood pressure; MAP, mean arterial pressure; HR, heart rate; SHR, spontaneously hypertensive rats.

were presented as the mean \pm standard error. $\mathrm{P}<0.05$ was considered to indicate a statistically significant difference.

\section{Results}

General data. The SBP of the tail artery in the conscious state and the baseline MAP of the femoral artery under anesthesia were significantly greater in SHRs compared with Wistar rats. There were no significant differences between Wistar rats and SHRs in body weight or baseline HR (Table I).

Dosage effects of hexamethonium. Intravenous injection of four doses $(0.2,1.0,5.0$ or $25.0 \mathrm{mg} / \mathrm{kg}$ body weight) of hexamethonium significantly reduced the RSNA, MAP and HR in the Wistar rats and the SHRs. There were no significant differences between Wistar rats and SHRs in the RSNA, MAP or $\mathrm{HR}$ at the 0.2 or $1.0 \mathrm{mg} / \mathrm{kg}$ doses. However, 5.0 and $25.0 \mathrm{mg} / \mathrm{kg}$ hexamethonium resulted in greater reductions in the RSNA and MAP in SHRs compared with Wistar rats (Fig. 1). Representative recordings indicate that the intravenous injection of $5.0 \mathrm{mg} / \mathrm{kg}$ of hexamethonium reduced the RSNA, MAP and HR (Fig. 2).

Association between RSNA and MAP. There was a significant positive correlation between the alterations in RSNA and MAP response to intravenous injection of hexamethonium in the Wistar rats and SHRs (Fig. 3).

Time at which hexamethonium reached its maximum effects. There was no significant difference between the SHRs and Wistar rats in the time course of the maximal effects of the four doses of hexamethonium on the RSNA, MAP or HR (Fig. 4).

Recovery time of hexamethonium. There were no significant differences between the SHRs and Wistar rats in the recovery time of the RSNA, MAP or HR at the four doses of hexamethonium investigated (Fig. 5).

Recovery from hexamethonium. RSNA fully recovered at the hexamethonium doses of 0.2 and $1.0 \mathrm{mg} / \mathrm{kg}$ and partially 
A

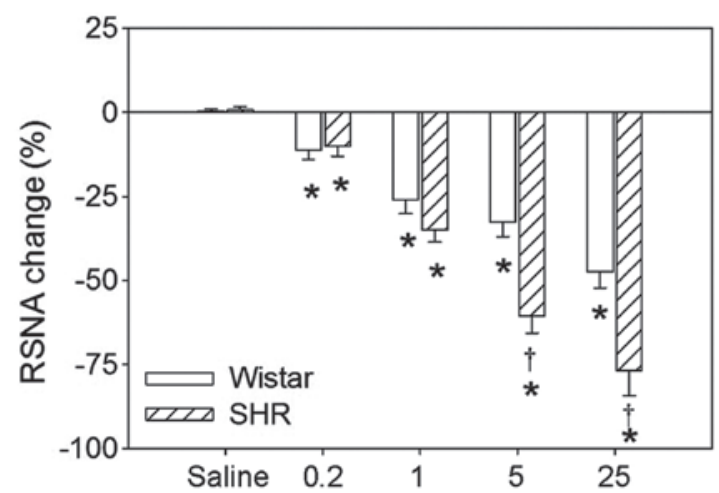

B

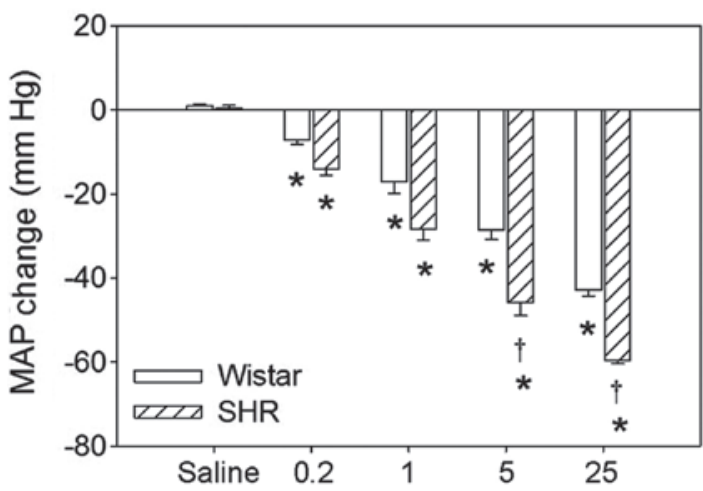

$\mathrm{C}$

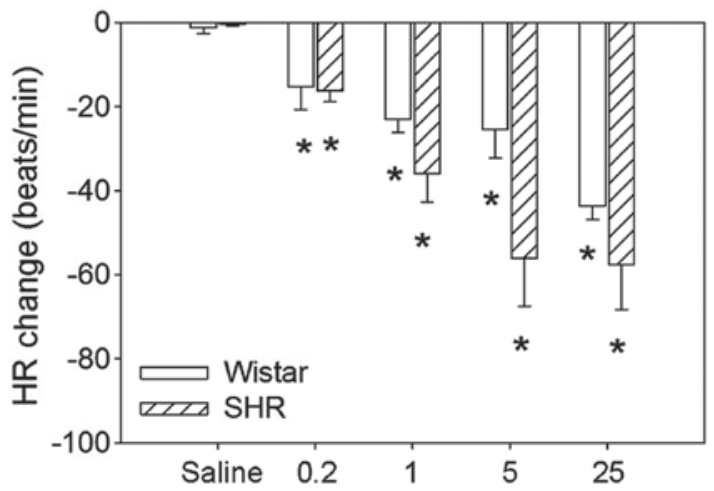

Figure 1. Dose effects of intravenous injection of hexamethonium. Effects of saline and hexamethonium (0.2, $1.0,5.0$ and $25.0 \mathrm{mg} / \mathrm{kg}$ body weight) on the (A) RSNA, (B) MAP and (C) HR in Wistar rats and SHRs. ${ }^{*} \mathrm{P}<0.05$ vs. saline; ${ }^{\dagger} \mathrm{P}<0.05$ vs. Wistar. $\mathrm{n}=6$ for each group. RSNA, renal sympathetic nerve activity; MAP, mean arterial pressure; HR, heart rate; SHR, spontaneously hypertensive rats.

A

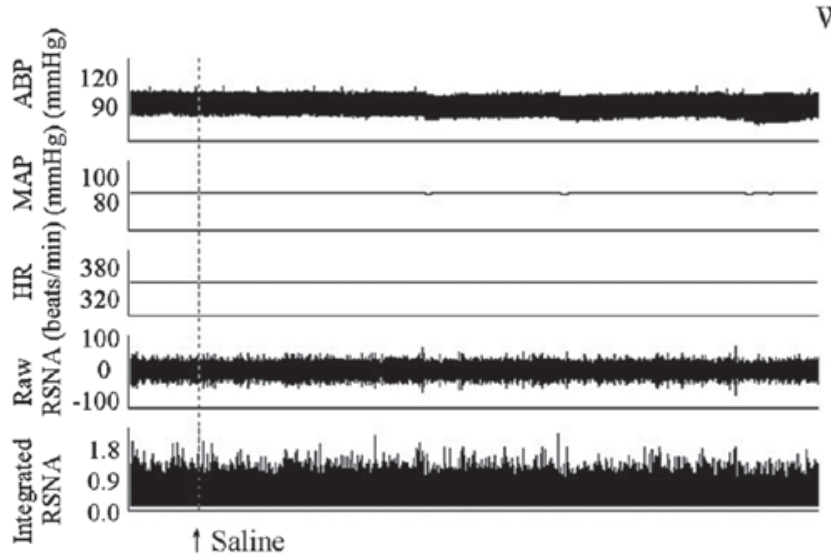

Wistar

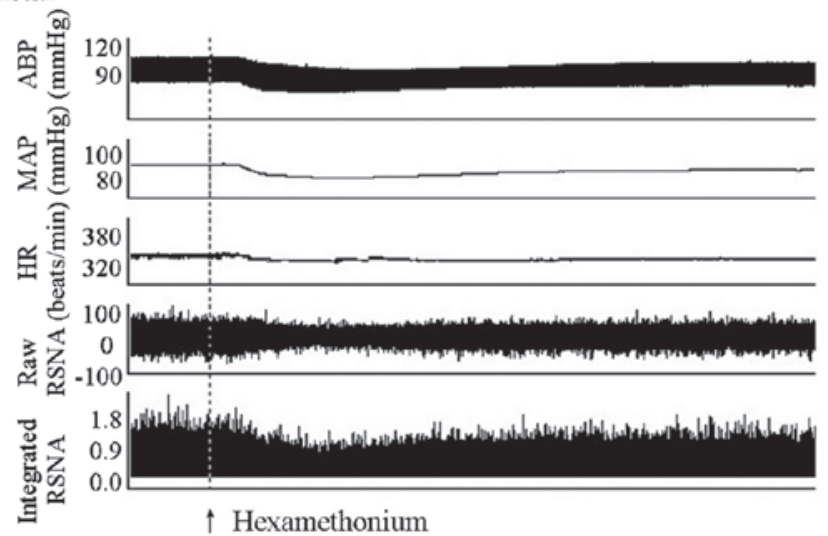

SHR

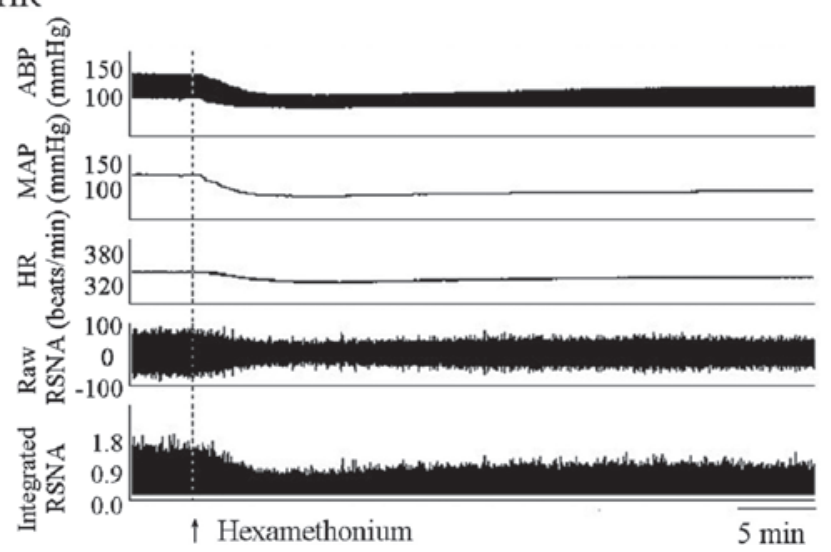

Figure 2. Representative recordings demonstrate the effect of the intravenous injection of saline and hexamethonium (5.0 mg/kg body weight) on RSNA, MAP and HR in (A) Wistar rats and (B) SHRs. ABP, arterial blood pressure; MAP, mean arterial pressure; HR, heart rate; RSNA, renal sympathetic nerve activity; SHR, spontaneously hypertensive rats. 
A

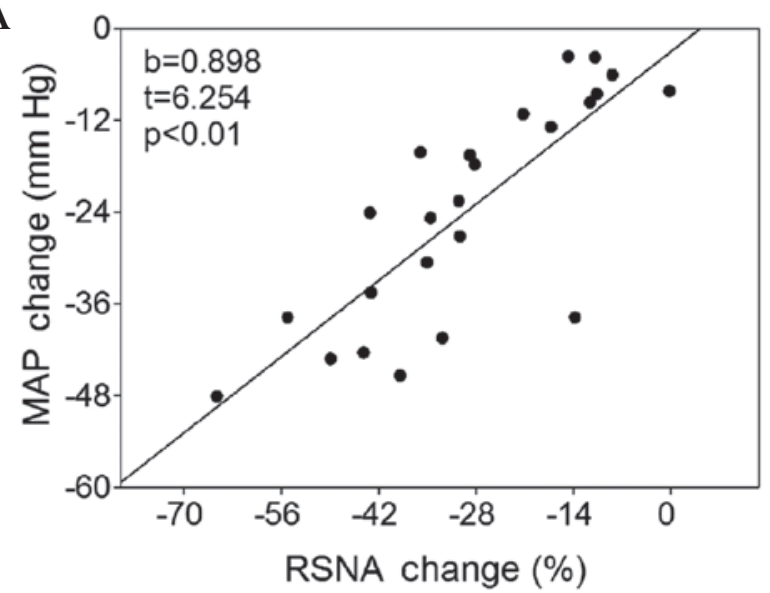

B

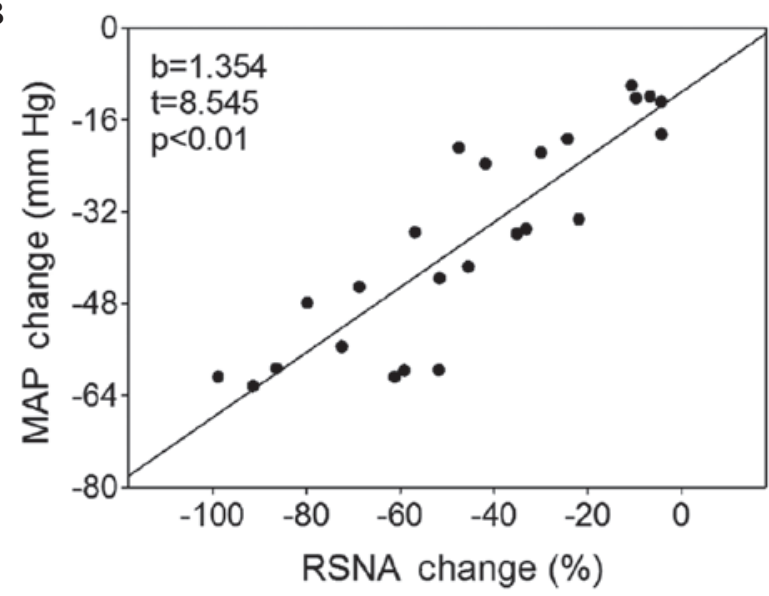

Figure 3. The association between RSNA and MAP response to hexamethonium intravenous injection in (A) Wistar rats and (B) SHRs. b, $\beta$ coefficient (standardized regression coefficient); $t$, $t$ value to measure the significance of the regression coefficient; MAP, mean arterial pressure; RSNA, renal sympathetic nerve activity; SHR, spontaneously hypertensive rats.
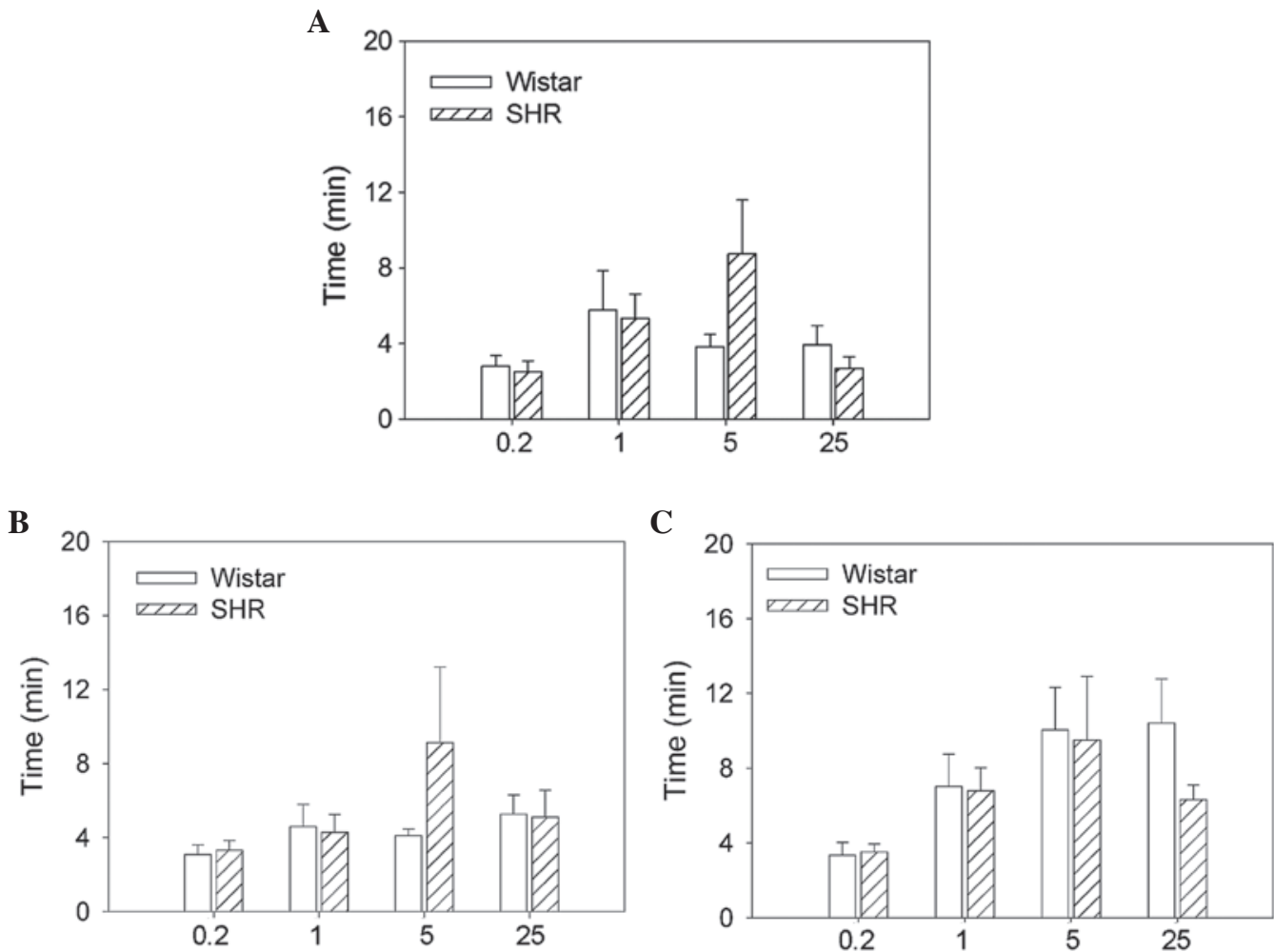

Figure 4. The time that hexamethonium $(0.2,1.0,5.0$ and $25.0 \mathrm{mg} / \mathrm{kg}$ body weight) reaches its maximum effects on (A) renal sympathetic nerve activity, (B) mean arterial pressure and $(C)$ heart rate in Wistar rats and SHRs. $P<0.05$ vs. saline; $P<0.05$ vs. Wistar. $n=6$ for each group. SHR, spontaneously hypertensive rats.

recov-ered at doses of 5.0 and $25.0 \mathrm{mg} / \mathrm{kg}$ (Fig. 5). MAP and HR were fully recovered at a dose of $0.2 \mathrm{mg} / \mathrm{kg}$ and partially recovere $d$ at doses of $1.0,5.0$ and $25.0 \mathrm{mg} / \mathrm{kg}$. There were no significant differences between the Wistar rats and SHRs in the recovery time of RSNA at the four doses of hexamethonium investigated $(0.2 \mathrm{mg} / \mathrm{kg}, 5.0 \pm 1.1$ vs. $5.2 \pm 1.4 \mathrm{~min}$; $1.0 \mathrm{mg} / \mathrm{kg}, 17.6 \pm 4.5$ vs. $13.1 \pm 1.8 \mathrm{~min} ; 5.0 \mathrm{mg} / \mathrm{kg}, 23.8 \pm 6.4$ vs. $16.6 \pm 6.1 \mathrm{~min}$; and $25.0 \mathrm{mg} / \mathrm{kg}, 12.8 \pm 3.4 \mathrm{vs} .21 .4 \pm 4.5 \mathrm{~min}$ ), MAP $(0.2 \mathrm{mg} / \mathrm{kg}, 7.6 \pm 1.1$ vs. $21.6 \pm 14.1 \mathrm{~min} ; 1.0 \mathrm{mg} / \mathrm{kg}, 25.9 \pm 10.5$ vs. $16.9 \pm 3.5 \mathrm{~min} ; 5.0 \mathrm{mg} / \mathrm{kg}, 70.1 \pm 11.5$ vs. $54.0 \pm 24.5 \mathrm{~min}$; and $25.0 \mathrm{mg} / \mathrm{kg}, 68.6 \pm 16.8$ vs. $57.0 \pm 12.9 \mathrm{~min})$ and HR $(0.2 \mathrm{mg} / \mathrm{kg}, 5.7 \pm 1.4$ vs. $11.0 \pm 1.1 \mathrm{~min} ; 1.0 \mathrm{mg} / \mathrm{kg}, 16.9 \pm 4.2$ vs. $16.1 \pm 4.5 \mathrm{~min} ; 5.0 \mathrm{mg} / \mathrm{kg}, 11.8 \pm 3.2$ vs. $15.6 \pm 4.6 \mathrm{~min}$; and $25.0 \mathrm{mg} / \mathrm{kg}, 15.5 \pm 4.8$ vs. $27.7 \pm 10.4 \mathrm{~min}$ ) (Fig. 6).

\section{Discussion}

Sympathetic activity is enhanced in patients with essential (1) or secondary hypertension $(2,3)$ and in various hypertensive models $(9,17,18)$. Excessive sympathetic output contributes to the pathogenesis of hypertension and the progression of organ damage (19-21). The therapeutic targeting of sympathetic activation is considered to be an effective antihypertensive strategy $(22,23)$. 
A

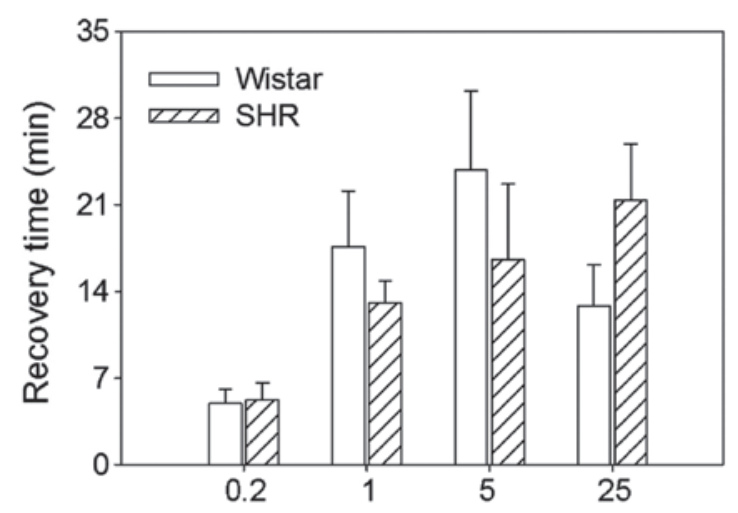

B

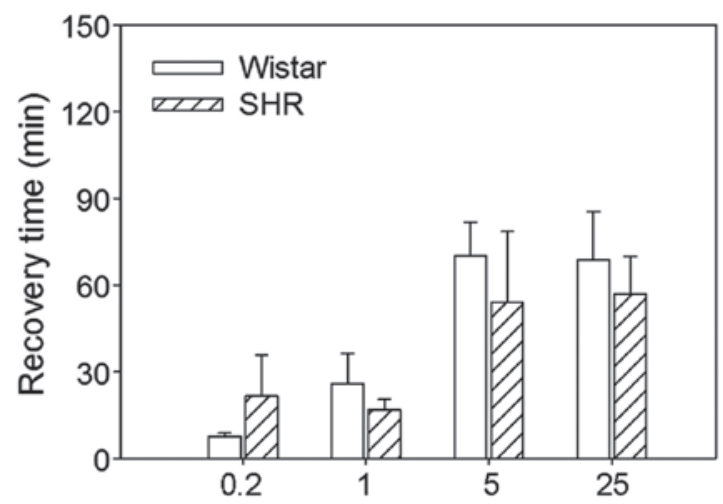

C

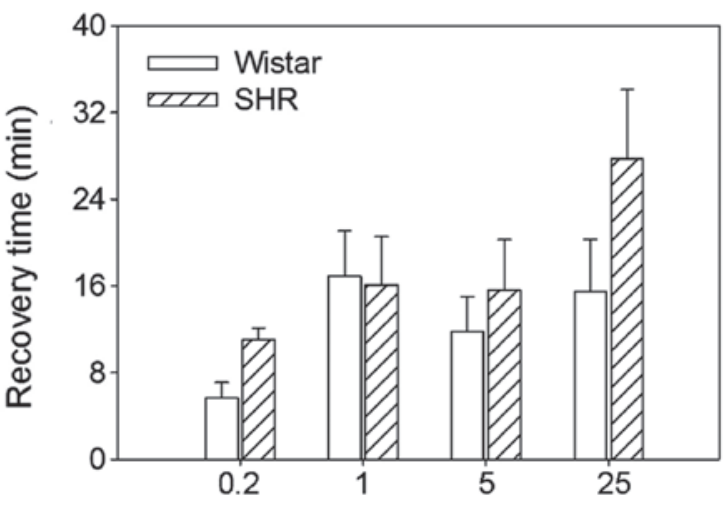

Figure 5. The recovery time of hexamethonium $(0.2,1.0,5.0$ and $25.0 \mathrm{mg} / \mathrm{kg}$ body weight) on the (A) renal sympathetic nerve activity, (B) mean arterial pressure and $(\mathrm{C})$ heart rate in Wistar rats and SHRs. $\mathrm{P}<0.05$ vs. saline; $\mathrm{P}<0.05$ vs. Wistar. $\mathrm{n}=6$ for each group. SHR, spontaneously hypertensive rats.

A

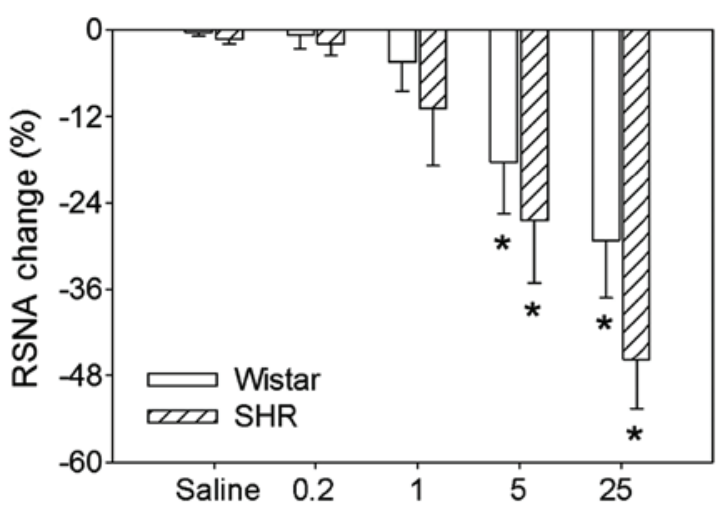

B

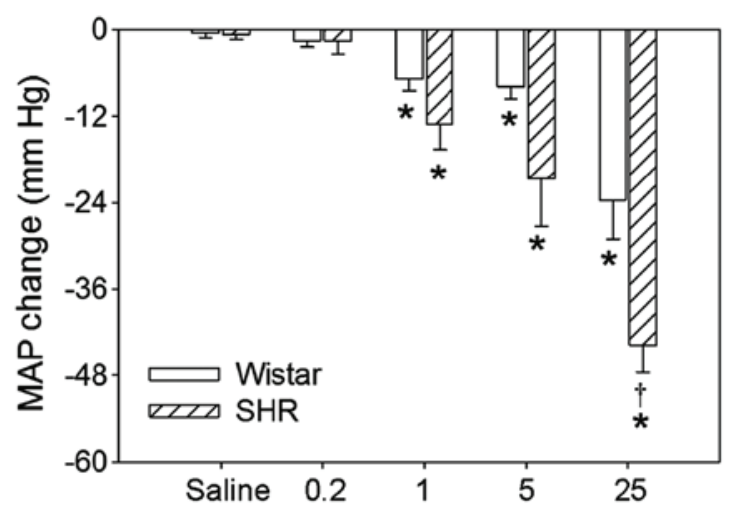

C

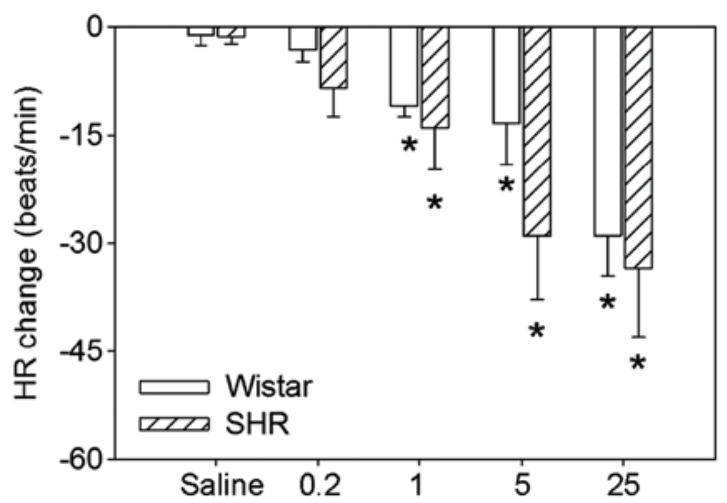

Figure 6. The recovery of (A) RSNA, (B) MAP and (C) HR response to the intravenous injection of saline or hexamethonium (0.2, 1.0, 5.0 and 25.0 mg/kg body weight), measured at their maximal points. ${ }^{*} \mathrm{P}<0.05$ vs. saline; ${ }^{\dagger} \mathrm{P}<0.05$ vs. Wistar. $\mathrm{n}=6$ for each group. RSNA, renal sympathetic nerve activity; MAP, mean arterial pressure; HR, heart rate; SHR, spontaneously hypertensive rats. 
The MAP response to ganglionic blockade has been used to evaluate basal sympathetic nerve activity in conscious rats (8). In the present study, the four doses of hexamethonium investigated were demonstrated to significantly reduce the RSNA, MAP and HR in the Wistar rats and the SHRs. The highest doses of hexamethonium $(5.0$ and $25.0 \mathrm{mg} / \mathrm{kg})$ resulted in a greater reduction in the RSNA and MAP in SHRs compared with Wistar rats. There was a significant positive correlation between the alterations in the RSNA and MAP response to hexamethonium in the Wistar rats and SHRs.

It has been demonstrated that the sympathetic activity of obese rats $(4,24)$, renovascular hypertensive rats $(5,25,26)$ and SHRs $(6,27,28)$ is enhanced compared with normotensive rats. Hexamethonium is a ganglionic blocker $(10,11)$ and reduces blood pressure in SHR and Wistar rats (8). In the present study, the intravenous injection of four doses $(0.2$, $1.0,5.0$ or $25.0 \mathrm{mg} / \mathrm{kg}$ body weight) of hexamethonium was demonstrated to significantly reduce the RSNA, MAP and HR in the Wistar rats and the SHRs. The highest doses of hexamethonium $(5.0$ and $25.0 \mathrm{mg} / \mathrm{kg})$ resulted in a greater reduction in the RSNA and MAP in SHRs compared with Wistar rats. There was a significant positive correlation between the alterations in RSNA and MAP in response to the intravenous injection of hexamethonium in the Wistar rats and SHRs. These data suggest that the MAP response to hexamethonium may be used to evaluate basal sympathetic nerve activity.

The current study investigated whether the time point at which hexamethonium reaches its maximum effect, the time course of recovery from hexamethonium or the extent of recovery from hexamethonium may be used to evaluate sympathetic activity. There were no significant differences observed in the timing of the maximal effects on RSNA, MAP and HR or in recovery following hexamethonium treatment, the RSNA was fully recovered at doses of 0.2 and $1 \mathrm{mg} / \mathrm{kg}$ and partially recovered at doses of 5.0 and $25.0 \mathrm{mg} / \mathrm{kg}$ hexamethonium. MAP and HR were fully recovered at a dose of $0.2 \mathrm{mg} / \mathrm{kg}$ and partially recovered at the doses of 1.0 , 5.0 and $25.0 \mathrm{mg} / \mathrm{kg}$ hexamethonium. Additionally, there were no significant differences between SHRs and Wistar rats in the recovery of RSNA, MAP and HR. These data suggest that the times at which hexamethonium reached its maximal effect, the recovery time course and the extent of recovery from hexamethonium are not suitable for use in the evaluation of sympathetic nerve activity.

In conclusion, 5.0 and $25.0 \mathrm{mg} / \mathrm{kg}$ hexamethonium resulted in a greater reduction in the RSNA and MAP in SHRs compared with Wistar rats. There was a significant positive correlation between the alterations in RSNA and MAP in response to the intravenous injection of hexamethonium in the Wistar rats and SHRs. The MAP response to ganglionic blockade by hexamethonium may be used to evaluate basal sympathetic nerve activity.

\section{Acknowledgements}

The authors would like to thank the Collaborative Innovation Center for Cardiovascular Disease Translational Medicine for their support, as well as the National Natural Science Foundation of China (grant no. 81400315).

\section{References}

1. Hogarth AJ, Mackintosh AF and Mary DA: The effect of gender on the sympathetic nerve hyperactivity of essential hypertension. J Hum Hypertens 21: 239-245, 2007.

2. Remuzzi G: Sympathetic overactivity in hypertensive patients with chronic renal disease. N Engl J Med 340: 1360-1361, 1999.

3. Neumann J, Ligtenberg G, Klein IH, Boer P, Oey PL, Koomans HA and Blankestijn PJ: Sympathetic hyperactivity in hypertensive chronic kidney disease patients is reduced during standard treatment. Hypertension 49: 506-510, 2007.

4. Xiong XQ, Chen WW, Han Y, Zhou YB, Zhang F, Gao XY and Zhu GQ: Enhanced adipose afferent reflex contributes to sympathetic activation in diet-induced obesity hypertension. Hypertension 60: 1280-1286, 2012.

5. Li P, Sun HJ, Cui BP, Zhou YB and Han Y: Angiotensin-(1-7) in the rostral ventrolateral medulla modulates enhanced cardiac sympathetic afferent reflex and sympathetic activation in renovascular hypertensive rats. Hypertension 61: 820-827, 2013.

6. Ye ZY, Li DP and Pan HL: Regulation of Hypothalamic Presympathetic Neurons and Sympathetic Outflow by Group II Metabotropic Glutamate Receptors in Spontaneously Hypertensive Rats. Hypertension 62: 255-262, 2013.

7. Sun HJ, Li P, Chen WW, Xiong XQ and Han Y: Angiotensin II and angiotensin-(1-7) in paraventricular nucleus modulate cardiac sympathetic afferent reflex in renovascular hypertensive rats. PLoS One 7: e52557, 2012.

8. Yuan N, Zhang F, Zhang LL, Gao J, Zhou YB, Han Y and Zhu GQ: SOD1 gene transfer into paraventricular nucleus attenuates hypertension and sympathetic activity in spontaneously hypertensive rats. Pflugers Arch 465: 261-270, 2013.

9. Fujita M, Ando K, Nagae A and Fujita T: Sympathoexcitation by oxidative stress in the brain mediates arterial pressure elevation in salt-sensitive hypertension. Hypertension 50: 360-367, 2007.

10. Burt CC and Graham AJ: Pentamethonium and hexamethonium iodide in investigation of peripheral vascular disease and hypertension. BMJ 1: 455-460, 1950

11. Bechgaard P, Iversen T and Nielsen AL: Hexamethonium therapy of essential hypertension. Ugeskr Laeger 113: 1335-1340, 1951. (In Danish)

12. Nunes FC and Braga VA: Chronic angiotensin II infusion modulates angiotensin II type I receptor expression in the subfornical organ and the rostral ventrolateral medulla in hypertensive rats. J Renin Angiotensin Aldosterone Syst 12: 440-445, 2011

13. França-Silva MS, Monteiro MM, Queiroz TM, Santos AF, Athayde-Filho PF and Braga VA: The new nitric oxide donor 2-nitrate-1,3-dibuthoxypropan alters autonomic function in spontaneously hypertensive rats. Auton Neurosci 171: 28-35, 2012.

14. Touw KB, Haywood JR, Shaffer RA and Brody MJ: Contribution of the sympathetic nervous system to vascular resistance in conscious young and adult spontaneously hypertensive rats. Hypertension 2: 408-418, 1980.

15. Sato Y, Ando K and Fujita T: Role of sympathetic nervous system in hypotensive action of taurine in DOCA-salt rats. Hypertension 9: 81-87, 1987.

16. Guide for the Care and Use of Laboratory Animals. 6th edition. National Research Council (US) Institute for Laboratory Animal Research. Washington, DC, USA, 1996.

17. Li DP and Pan HL: Role of gamma-aminobutyric acid (GABA) $A$ and GABAB receptors in paraventricular nucleus in control of sympathetic vasomotor tone in hypertension. J Pharmacol Exp Ther 320: 615-626, 2007.

18. Katholi RE, Whitlow PL, Winternitz SR and Oparil S: Importance of the renal nerves in established two-kidney, one clip Goldblatt hypertension. Hypertension 4: 166-174, 1982.

19. Rahn KH, Barenbrock $M$ and Hausberg M: The sympathetic nervous system in the pathogenesis of hypertension. J Hypertens Suppl 17: S11-S14, 1999.

20. Mancia G, Grassi G, Giannattasio C and Seravalle G: Sympathetic activation in the pathogenesis of hypertension and progression of organ damage. Hypertension 34: 724-728, 1999.

21. Morise T, Horita M, Kitagawa I, Shinzato R, Hoshiba Y, Masuya H, Suzuki M and Takekoshi N: The potent role of increased sympathetic tone in pathogenesis of essential hypertension with neurovascular compression. J Hum Hypertens 14: 807-811, 2000. 
22. Del Colle S, Morello F, Rabbia F, Milan A, Naso D, Puglisi E, Mulatero P and Veglio F: Antihypertensive drugs and the sympathetic nervous system. J Cardiovasc Pharmacol 50: 487-496, 2007.

23. Fisher JP and Fadel PJ: Therapeutic strategies for targeting excessive central sympathetic activation in human hypertension. Exp Physiol 95: 572-580, 2010.

24. Balasubramanian P, Sirivelu MP, Weiss KA, Wagner JG, Harkema JR, Morishita M, Mohankumar PS and Mohankumar SM: Differential effects of inhalation exposure to PM2.5 on hypothalamic monoamines and corticotrophin releasing hormone in lean and obese rats. Neurotoxicology 36: 106-111, 2013.

25. Zhou H, Sun HJ, Chang JR, Ding L, Gao Q, Tang CS, Zhu GQ and Zhou YB: Cardiac sympathetic afferent reflex response to intermedin microinjection into paraventricular nucleus is mediated by nitric oxide and $\gamma$-amino butyric acid in hypertensive rats. Exp Biol Med (Maywood) 239: 1352-1359, 2014.
26. Zhang LL, Ding L, Zhang F, Gao R, Chen Q, Li YH, Kang YM and Zhu GQ: Salusin- $\beta$ in rostral ventrolateral medulla increases sympathetic outflow and blood pressure via superoxide anions in hypertensive rats. J Hypertens 32: 1059-1067, 2014.

27. Maranon RO, Lima R, Mathbout M, do Carmo JM, Hall JE, Roman RJ and Reckelhoff JF: Postmenopausal hypertension: Role of the sympathetic nervous system in an animal model. Am J Physiol Regul Integr Comp Physiol 306: R248-R256, 2014.

28. Shanks J, Manou-Stathopoulou S, Lu CJ, Li D, Paterson DJ and Herring N: Cardiac sympathetic dysfunction in the prehypertensive spontaneously hypertensive rat. Am J Physiol Heart Circ Physiol 305: H980-H986, 2013. 